\title{
ACTION OF TRIPLOID INDUCER (tri) ON MEIOSIS IN BARLEY (HORDEUM VULGARE L.)
}

\author{
R. A. FINCH and M. D. BENNETT \\ Plant Breeding Institute, Maris Lane, Trumpington, Cambridge CB2 $2 L Q$
}

Received 2.iv.79

\section{Summary}

The tri gene has a unique effect on barley meiosis. It suppresses second division in about 50 per cent of embryo sac mother cells (emc's) at random so that diploid embryo sacs are formed. Otherwise, meiosis is regular in all emc's and female fertility is normal in all spikes. However, tri does not similarly affect pollen mother cells (pmc's). Meiosis is regular in over 80 per cent of pmc's and fertility on selfing is normal. A maximum of only $1 \cdot 2$ per cent of pmc's and pollen grains have a doubled chromosome number, but extra chromosomes occur in 0-20 per cent (mean 10 per cent) of pmc's, probably through spindle abnormalities at the last premeiotic mitosis.

The tri gene has cytogenetic potential for aneuploid and polyploid production and centromere mapping. If it occurs in the wild, it may play a significant role in Hordeum evolution.

\section{INTRODUCTION}

Ahokas (1977) described a recessive mutant gene which he named " triploid inducer" (tri) in a single plant selection of the Finnish barley variety, Paavo. Diploid plants $(2 n=14)$ of his P-4 stock, which is homozygous for tri, are fully viable and of normal fertility but have two types of seed distributed in equal numbers at random within all spikes. One type has normal endosperm and a diploid embryo but the other has a thin endosperm and a triploid embryo $(2 n=21)$. In crosses with normal barley, P-4 diploids yielded Fl progenies comprising diploids and triploids when P-4 was the female parent, but only diploids when P-4 was the male. The above facts, which we have confirmed using P-4 seeds kindly supplied by Dr Ahokas, point to a mechanism by which the chromosome number is exactly doubled on the female side in 50 per cent of florets but is normal on the male side. This implies several unusual possibilities in genetics and evolution (see discussion). They also point to a precise morphogenetic segregation within a homozygous spike whose basis is unknown. Both practical and theoretical interest therefore attaches to the work reported in the present paper which shows when tri is expressed in development and discusses its possible mode of action, uses in genetics and significance in evolution.

\section{MAterials AND MEthods}

(i) Genotypes. Seeds of Paavo (2x) and P-4 (2x and $3 \mathrm{x})$ were kindly supplied by Dr H. Ahokas (Genetics Department, Helsinki University). Diploid Sultan and Vada barleys were obtained from stocks at the Plant 
Breeding Institute, Cambridge. Bulbs of $2 \mathrm{x}$ Hordeum bulbosum L. clone 5I-44 were kindly supplied by Dr G. J. Jensen (Risø).

(ii) Plant Culture. Seeds were germinated on damp filter paper at $20-24^{\circ} \mathrm{C}$ in the dark. Seedlings were potted in John Innes No. 2 compost and grown in glasshouses to the juvenile stage or beyond. Barley for use in cytological studies of fixed spikes was grown in a glasshouse artificially lit for 18 or 24 hours per day at day/night temperatures of $20 / 15 \pm 5^{\circ} \mathrm{C}$. Plants were transferred to a growth room at $20 \pm 1^{\circ} \mathrm{C}$ with continuous light 3 or more days before fixation. Barley used for seed production was grown in a frost-free, unlit glasshouse in spring and flowered in summer.

(iii) Cytological preparations. Material was fixed in Carnoy's solution, excised and usually stained by the Feulgen method and squashed in acetocarmine. Unless otherwise stated, root tips were pre-treated for 24 hours in ice-water or 4 hours in saturated aqueous 1-bromonaphthalene. To observe relatively undistorted pollen mother cells (pmc's) and embryo sac mother cells (emc's), some anthers were tapped gently in aceto-carmine without hydrolysis and some ovules were observed in optical section without a coverslip. DNA $C$ values of selected Feulgen-stained nuclei in female dyads and tetrads, young embryo sacs, endosperms and embryos were estimated in squashes using a Vickers M86 scanning microdensitometer (Bennett and Smith, 1976). Fluorescing cell walls of dyads, tetrads and young embryo sacs in fixed ovules lightly squashed in $0 \cdot 1$ per cent $w / v$ aniline blue in $0 \cdot 1 \mathrm{M}$ aqueous $\mathrm{K}_{3} \mathrm{PO}_{3}$ were observed by transmitted $\mathrm{UV}$ light $(300-400 \mathrm{~nm})$ from a $200 \mathrm{~W} \mathrm{HBOHg}$ vapour lamp with a $3 \mathrm{~mm}$ BG.12 exciter filter in a Vickers M4l photoplan microscope (Ramanna and Mutsaerts, 1971).

(iv) Crossing. Haploids and P-4 diploids were raised from barley $\times$ $H$. bulbosum crosses as outlined by Jensen (1976).

\section{RESUlts}

(i) Time of tri expression in P-4 female development

Ahokas (1977) suggested that abnormal P-4 seed might result from reversal of developmental roles of fertilised egg and primary endosperm nuclei so that a diploid endosperm accompanies a triploid embryo. However, in the present study, all abnormal P-4 embryo sacs from florets fixed 24 hours after pollination by Sultan or Vada had pentaploid endosperm. Nuclear DNA content measurements and/or chromosome counts from 30 embryo sacs showed that all endosperms were pentaploid (5-10C DNA content) or triploid (3-6C DNA content) accompanied respectively by triploid (3-6C DNA content) or diploid (2-4C DNA content) embryos. Furthermore, in each of 23 immature embryo sacs at stages from about the first to last mitoses (pollen in accompanying anthers uninucleate or at second mitosis, respectively), all mitotic nuclei were diploid (8 sacs) or haploid (15 sacs). No abnormalities except in chromosome number as

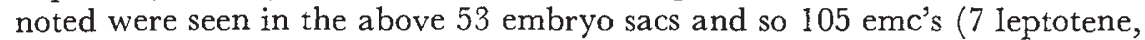
12 zygotene, 53 pachytene, 6 diplotene, I diakinesis, 6 metaphase I, 4 interphase (dyad stage), 8 prophase II, 3 metaphase II, 3 anaphase II and 2 telophase II) were studied. No abnormality was noticed. The mean chiasma frequency per cell in five emc's (14.40) from three plants was not 


\section{Plate I}
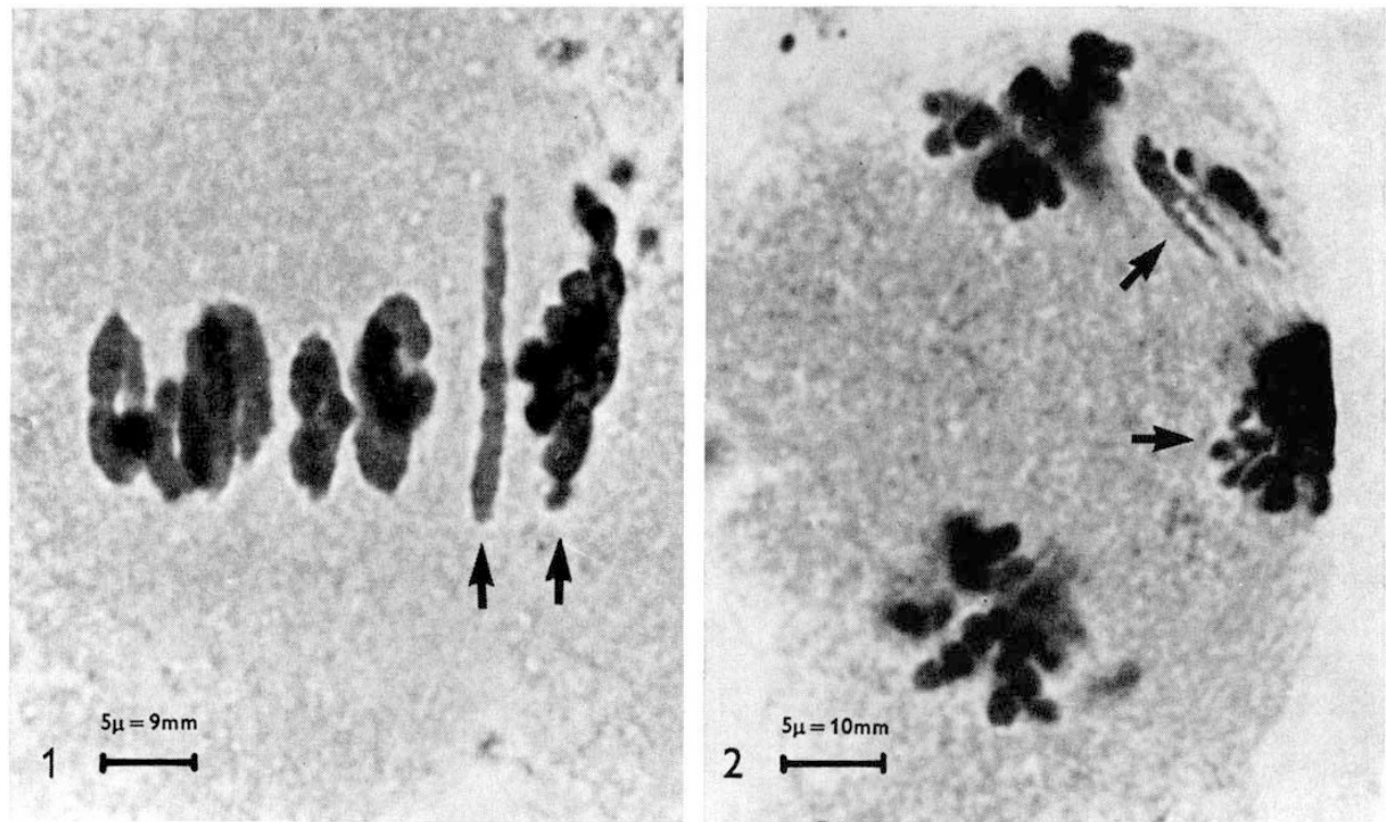

Fig. 1-2.-P-4 pmc's at metaphase I (fig. 1) and anaphase I (fig. 2) with extra chromosomes arrowed (Bars $=5 \mu \mathrm{m})$. 
significantly lower than that in five normal P-4 pmc's (15.20) from the same spikes. The absence of unreduced monads from the sample of 16 emc's at prophase II to telophase II indicates that anaphase I was normal. Thus, tri is expressed either at second meiotic division or so early in embryo sac development that diploid nuclei occur in the earliest mitoses.

To distinguish between meiotic and post-meiotic expression of tri, 80 ovules were chosen at random from florets with anthers $1.50-1.75 \mathrm{~mm}$ long, since other studies in P-4 (Finch and Bennett, unpublished) had shown that over 90 per cent of such florets contained ovules in which meiosis had ended but first embryo sac mitosis had not begun. In this sample of ovules, 40 contained an apparently normal dyad, 1 a dyad with micronuclei in the distal (micropylar) cell, 34 a normal tetrad, 4 a normal meiocyte (metaphase I-telophase II) and 1 a normal embryo sac at first mitosis. In a randomly chosen subsample of these ovules, 11 dyads and 9 tetrads were identified only by fluorescence. In a further subsample, nuclear DNA contents were estimated by microdensitometry. In each of five dyads, two $2 C$ nuclei or one $2 C$ nucleus and one $3 C$ or $4 C$ nucleus were found. In each of five tetrads, three $1 C$ nuclei were found, accompanied in three cases by a $1 C$ or $2 C$ nucleus. These results indicate that tri acts in about 50 per cent of emc's at second division and not after meiosis. Whether affected emc's omit this division altogether or undergo restitution after prophase or metaphase is uncertain. No evidence was found that a second division occurs in only one cell of a dyad, leading to triad formation.

Further evidence that tri affects female development at the second meiotic division comes from the progeny of haploids $(2 n=x=7)$. Florets from 10 Paavo haploids (170 florets) and 10 P-4 haploids (171 florets) were pollinated with Sultan or Vada pollen, giving seedsets of 5.3 per cent (nine seeds) and $2 \cdot 3$ per cent (four seeds), respectively. Interestingly, the aggregate seedset is vastly above $(\mathrm{P}<0.001)$ that calculated for haploid barley from the formula, 100/2n per cent (Swanson, 1958, p. 179). All seeds germinated and gave normal diploid plants except two from the P-4 haploid which gave a triploid $(2 n=2 \mathrm{I})$ and a hypotriploid $(2 n=20)$. Meiotic first division in haploids usually leads to deficient cells in the dyad and hence sterility, but suppression of first division should allow regular second division, yielding euhaploid cells, one of which should form a normal embryo sac, thus restoring fertility. However, seedset on the P-4 haploid was about half that on the control and far short of the 50 per cent expected if tri had suppressed first division in 50 per cent of emc's. Nevertheless, tri did act in haploid P-4, since the progeny was half triploid or hypotriploid and half diploid, not uniformly diploid as in the control. The egg that gave rise to the hypotriploid must have had 13 chromosomes. It probably arose after reductional division of six chromosomes and equational division of one chromosome at anaphase $I$ and suppression of second division so that an embryo sac with a 13-chromosome nucleus developed. Univalents are known to divide reductionally or equationally at anaphase $I$ in haploid barley pmc's (Sadasivaiah and Kasha, 1971). Post-meiotic chromosome doubling cannot yield a nucleus with 13 chromosomes and our evidence is that irregular mitoses (which could give 13-chromosome nuclei) are absent from or very rare in P-4 embryo sacs. Thus, no aneuploid counts were obtained in root tips from 302 diploid and 105 triploid seeds from P-4 diploids and no irregular mitosis was seen in any embryo sac squash. 


\section{(ii) Male development in P-4}

In contrast with the female side, most pmc's, tetrads and pollen grains developed normally and only 0.2 per cent of male gametophytes were diploid at first mitosis. In samples of 1000 , only 1 per cent of pmc's formed a dyad after meiosis, though 1.2 per cent were tetraploid $(n=14)$ with apparently regular meiosis at metaphase $I$ and 0.1 per cent were so at metaphase II. In different anthers, $0-20$ per cent (mean about 10 per cent) of pmc's had extra chromosomes in addition to the normal 14. One pmc had about 24 extra chromosomes but most pmc's had 2 to 14 . Extra chromosomes were sometimes completely integrated in development with normal chromosomes, as in pmc's with 28 chromosomes and regular meiosis, but they were usually more or less different from normal ones in position and timing. Thus extra chromosomes often formed a group which was distinctly more peripheral in the pmc than the rest at meiotic prophase; and at metaphase I, extra chromosomes were usually clumped together beyond the edge of the normal equatorial plate extending above and below it close to the pmc wall, while seven normal bivalents occupied a more central position (fig. 1). In some pmc's, extra chromosomes were in the pachytene state when more central ones were at diplotene. In some metaphase I pmc's, extra chromosomes were abnormally thin and attenuated. All intergradations between retarded peripheral and normal central chromosomes apparently occurred. Chiasma frequencies in the central and many extra bivalents of abnormal pmc's were similar to those of bivalents in normal P-4 and Paavo pmc's. A few $(<0.2$ per cent) metaphase I pmc's, had one ring quadrivalent and about 0.4 per cent of diploid pmc's were achiasmate. At anaphase I, the more central chromosomes disjoined normally, while peripheral extra chromosomes usually stretched towards the poles but did not complete normal anaphase movements (fig. 2). Chromosomes in intermediate positions often disjoined normally. In most pmc's with extra chromosomes, micronuclei and bridges formed after anaphase I and further irregular development led to giant, minute, multinucleate or fused pollen grains, most or all of which were not functional. In Paavo control anthers, abnormalities were seen in 2 of 1359 cells at metaphase I to dyads, 4 of 822 tetrads and 0 of 1000 first pollen mitoses.

\section{(iii) Mitotic instability in P-4}

It is clear that tri does not cause general mitotic instability. Thus one or more pretreated root tips were examined from over 40 haploid, 500 diploid and 100 triploid young P-4 plants or seedlings and no abnormality was seen except in two roots, one from a haploid and one from a diploid, where all mitoses were diploid and tetraploid, respectively. No abnormality was seen in non-pretreated roots from five diploid seedlings or in somatic tissues of several hundred ovules and anthers of P-4, except for two adjacent cells with dumb-bell shaped nuclei in one ovule. Lesser quantities of Paavo material revealed no abnormalities.

\section{Discussion}

(i) Effect of tri on P-4 meiosis

Except for suppression of second division in about 50 per cent of ovules, meiosis was regular in emc's and no extra chromatin was noticed in about 
200 ovules, the micronuclei seen in one dyad representing nuclear fragmentation, not increase of chromatin. By contrast, the most frequent irregularities in pmc development were clearly associated with extra chromosomes. Such chromosomes were peripheral in pmc's and multivalents were rare, indicating that extra chromosomes were usually not integrated with central ones. Since somatic instability was rare in roots, anthers and ovules, upsets leading to extra chromosomes in pmc's probably occurred during the later archesporial mitoses. The rarity of cells above the tetraploid level suggests that such upsets occurred mainly at the last premeiotic mitosis. Failure in premeiotic spindle function or cytokinesis or both is, therefore, a probable main cause of irregularities in pmc meiosis, whereas upsets leading to rare achiasmate cells and post-meiotic dyads probably arose in the pmc's themselves. Thus meiotic irregularies originate in about 50 per cent of ovules specifically at second meiotic division; but in 0-20 per cent of final archesporial mitoses in anthers. There is hence little in common between emc and pmc irregularities and the latter may not be due to tri. A possible link is spindle failure if emc's undergo an abortive second division.

The mechanism whereby tri affects emc's and pmc's differently is obscure but may be based on such differences between anther and ovule as the number, shape and physiology of meiocytes. Even more perplexing is the way in which tri seems to affect 50 per cent of emc's at random. This cannot be by nuclear gene segregation at anaphase I, for P-4 is homozygous for tri. Thus Ahokas (1977) showed that the gene is transmitted via egg or pollen and we have found that haploids produced from P- $4 \times$ $H$. bulbosum crosses, when doubled with colchicine and allowed to self, segregate diploid and triploid seeds, as do untreated diploids (which are of normal fertility) from the same cross. P-4 has normal fertility and so undetected segregation of cytoplasmic or genic lethals cannot occur. The frequencies of triploid and diploid seeds are the same in our growth room at $20^{\circ} \mathrm{C}$ with continuous light (Finch and Bennett, unpublished) as in the field in Finland (Ahokas, 1977) and so the segregation of normal and abnormal emc's within a plant is not noticeably influenced by such environmental differences.

\section{(ii) Uses of tri in cytogenetics}

P-4 is not only a ready source of triploids, as noted by Ahokas (1977), but also has potential for making new aneuploids and polyploids. For instance, triploid $\times$ diploid crosses should yield primary trisomics (cf. Tsuchiya, 1964). Such trisomics should have many embryo sacs derived from a disomic cell of a tri-induced post-meiotic dyad so having tetrasomic diploid eggs. Pollination of P-4 trisomics with Hordeum bulbosum, whose chromosomes would be eliminated (Subrahmanyam and Kasha, 1973), should therefore give tetrasomic plants. The yield of primary tetrasomics by this means may exceed that of previous methods which rely on rarelyfunctional disomic haploid pollen (Tsuchiya, 1964). Another advantage of this projected method is that all 16-chromosome plants would be tetrasomics and none double trisomics. The hypotriploid mentioned in our results is an example of the realisation of similar possibilities. Rhoades and Dempsey (1966) used the elongate gene, whose action resembles that of tri, to obtain penta-, hexa-, and heptaploid maize. It should also be possible 
to obtain polyploid barleys, since tri apparently acts in tetraploid plants the same as in diploids (Finch, unpublished).

Since tri suppresses second meiotic division, it may be useful in estimating linkages between marker genes and centromeres. In a tri homozygote which is heterozygous for a marker, the proportion of diploid embryo sacs that are heterozygous for the marker will be related to the frequency of cross-overs between the marker and the centromere. By pollinating with $H$. bulbosum, which is eliminated during embryo development, the products of the diploid sacs can be observed without the addition of a male genome. The feasibility of this method of sampling female gametes was proved in the present study: 15 per cent of P-4 florets gave dihaploids without colchicine treatment after pollination with $H$. bulbosum and embryo culture in addition to the haploids raised from a further 8 per cent. This method of linkage estimation has advantages over using interchanges or telotrisomics in that markers on all chromosomes can be assayed simultaneously in a single plant and the weak phenotypes of telotrisomics are avoided. Progeny tests could substitute for the use of $H$. bulbosum. Thus Rhoades and Dempsey (1966) obtained centromere recombination frequencies in elongate maize without eliminating the male genome.

\section{(iii) Occurrence and evolutionary potential of genes like tri}

The action of tri at meiosis presents a unique combination of several unusual features. Thus tri is expressed in a sexual diploid in 50 per cent of emc's, but not in the rest or (except perhaps in a low and variable fraction of premeiotic cells) on the male side; and it acts specifically at second division and without leading to sterility. Low frequency failure of one meiotic division is widespread in plants and animals (Darlington, 1965, tables 62, 65, 67; Harlan and de Wet, 1975; Beatty, 1978), but high frequencies are usually associated with apomixis (Lewis and John, 1963, table 65), abnormal first division (Dowrick, 1953; Rhoades and Dempsey, 1966) or laggards due to pairing failure (Wagenaar, 1968). Elongate maize differs from P-4 in that, inter alia, the proportion of shrivelled grains varied greatly from ear to ear, 18 per cent of triploid embryos were aneuploid and many ovules were sterile (Rhoades and Dempsey, 1966). In Saccharum officinarum, where unreduced gametes are exceptionally common on both male and female sides for a sexual species, doubling on the female side occurs usually after meiosis (Bremer, 1949). In Solanum tuberosum, genetic evidence indicated first division restitution in 75 per cent of dihaploid emc's (Ross and Langton, 1974) and second division restitution in 61 per cent of tetraploid emc's (Taylor, 1978). However, the restitution mechanism is unclear and may involve only small changes in spindle polarity as in pmc's, which regularly remain as monads throughout meiosis (Sosa and Hernández de Sosa, 1971). Furthermore, these high frequencies of restitution accompany low fertility and may therefore be artefacts of selective recovery of restitution products. Perhaps the closest comparison with tri is in animal apomicts like Rhabditis monohystera where second division fails in most oocytes after normal first division and male meiosis is normal throughout (Bělař, 1923).

The action of tri in causing genome doubling contrasts in evolutionary potential with that of genes controlling genome elimination in many 
Hordeum hybrids (Subrahmanyam, 1976, 1977). The tri gene apparently arose spontaneously in cultivated Paavo (Ahokas, 1977) and may also exist in the wild. If it does, it may have had an important evolutionary role within the genus Hordeum.

\section{REFERENCES}

AHOKas, H. 1977. A mutant of barley: triploid inducer. Barley Genet. Newsl., 7, 4-6.

BEATTY, R. A. 1978. The origin of human triploidy: an integration of qualitative and quantitative evidence. Ann. Hum. Genet., 41, 299-314.

BĔLAŘ, K. 1923. Über den Chromosomenzyklus von parthenogenetischen Erdnematoden. Biol. Zbl., 43, 513-518.

BenNetT, M. D., AND smith, J. в. 1976. Nuclear DNA amounts in angiosperms. Phil. Trans. R. Soc. Ser. B., 274, 227-274.

BREMER, G. 1949. Increase of chromosome numbers in species hybrids of Saccharum. Proc. 8th Int. Cong. Genet. pp. 541-542. Hereditas Suppl.

DARlington, c. D. 1965. Cytology. J. and A. Churchill, London.

DOWRICK, G. J. 1953. The chromosomes of Chrysanthemum. III. Meiosis in C. atratum. Heredity, 7, 219-226.

HARLAN, J. R., AND DE WET., J. M. J. 1975. On Ö. Winge and a prayer: the origins of polyploidy. Bot. Rev., 41, 361-390.

JENSEN, c. J. 1976. Barley monoploids and doubled monoploids : techniques and experience. In Barley Genetics III, ed. H. Gaul, pp. 316-345. Karl Thiemig, München.

LEwis, K. R., AND John, B. 1963. Chromosome Marker. J. and A. Churchill, London.

RAMANNA, M. S., AND MUTSAERTs, M. C. A. 1971. Unusual behaviour of growing pollen tubes in the styles and ovules of Spinacia oleracea L. Euphytica, 20, 145-151.

RHOADES, M. M., AND DEMPSEY, E. 1966. Induction of chromosome doubling at meiosis by the elongate gene in maize. Genetics, 54, 505-522.

ROSs, H., AND LANGTON, F. A. 1974. Origin of unreduced embryo sacs in diploid potatoes. Nature, 247, 378-379.

SADASIVAIAH, R. S., AND KASHA, K. J. 1971. Meiosis in haploid barley-an interpretation of non-homologous chromosome associations. Chromosoma, 35, 247-263.

SOSA, R., AND HERNÁNDEZ DE SOSA, M. 1971. Use of dihaploids in the breeding of Solanum tuberosum L. Hereditas, 69, 83-100.

SUBRAHMANYAM, N. c. 1976. Interspecific hybridization, chromosome elimination and haploidy in Hordeum. Barley Genet. Newsl., 6, 69-70.

subrahmanyam, N. c. 1977. Haploidy from Hordeum interspecific crosses. I. Polyhaploids of $H$. parodii and $H$. procerum. Theor. Appl. Genet., 49, 209-217.

SUBRAHMANYAM, N. c., AND KASHA, K. J. 1973. Selective chromosomal elimination during haploid formation in barley following interspecific hybridization. Chromosoma, 42, 111-125.

swanson, C. P. 1958. Cytology and Cytogenetics. MacMillan, London.

TAYLOR, L. M. 1978. Variation patterns of parthenogenetic plants derived from " unreduced" embryo sacs of Solanum tuberosum subspecies andigena (Juz. et Buk.) Hawkes. Theor. Appl. Genet., 52, 241-249.

rsuchrya, T. 1964. Chromosome aberrations and their use in genetics and breeding in barley-trisomics and aneuploids. In Barley Genetics I, eds. S. Broekhuizen, G. Dantuma, H. Lamberts and W. Lange, pp. 116-150. Centre for Agricultural Publications and Documentation, Wageningen.

WAgenaAR, E. B. 1968. Meiotic restitution and the origin of polyploidy. II. Prolonged duration of metaphase I as causal factor of restitution induction. Can. 7. Genet. Cytol., $10,844-852$. 